\title{
Simulídeos (simuliidae: diptera) como objeto de estudo no Brasil e no mundo
}

Os Artrópodes constituem um filo que corresponde a cerca de $75 \%$ das espécies do planeta, e dentro dessa ordem, encontra-se a Classe dos insetos, principalmente os pertencentes à Ordem Diptera, que correspondem há mais de 150 mil espécies já descritas em todo o mundo. Os simulídeos, inseridos na subordem Nematocera com uma ampla distribuição geográfica, são organismos que apresentam uma grande importância médico-veterinária, por serem transmissores de patógenos, como vermes do gênero Mansonella e Onchocerca, que afetam tanto os seres humanos quanto os animais. Os simulídeos são animais que apresentam uma importância ambiental notável, onde devido ao aumento das concentrações de matérias orgânicas nos rios e ao aporte de dejetos domésticos, agrícolas e industrias, permitem que esses insetos possam ser considerados como organismos bioindicadores da qualidade do ambiente. Filogeneticamente, os simulídeos são um importante grupo na base dos Diptera, que correspondem aos mosquitos e moscas, cujos aspectos evolutivos têm sido pouco estudados. Uma vez que os estudos de desenvolvimento embrionário dos Diptera se restringem em sua maior parte à mosca-da-fruta Drosophila melanogaster, estudos de biologia do desenvolvimento de simulídeos são importantes para compreender aspectos evolutivos fundamentais da evolução do grupo. No presente artigo discutiremos a importância de se estudar os aspectos negligenciados desta numerosa Ordem de insetos.

Palavras-chave: Mosquitos; Borrachudos; Ecologia; Genética.

\section{Simulium (similiidae: diptera) as a study in Brazil and the world}

Arthropods constitute a phylum that corresponds to about $75 \%$ of the planet's species, and within that order, there is the Class of insects, mainly those belonging to the Order Diptera, which correspond to more than 150 thousand species already describer in the world. The simulids, inserted in the suborder Nematocera with a wide geographical distribution, are organisms that have medical-veterinary importance, as they transmit pathogens, such as worms of the genus Mansonella and Onchocerca, which affect both humans and animals. The simulids are animals that have a remarkable environmental importance, where due to the increase in the concentration of organic matter in rivers and the contribution of domestic, agricultural and industrial waste, they allow these insects to be considered as bioindicator of environmental quality. Phylogenetically, simulids are an important group at the base of the Diptera, which correspond to mosquitões and flies, whose evolutionary aspects have bee little studied. Since Diptera's embryonic development studies are mostly restricted to the fruit fly Drosophila melanogaster, studies on the developmental biology of simulids are important to understand fundamental evolutionary aspects of the group's evolution. In this article we will discuss the importance of studying the neglected aspects of this numerous Order of insects.

Keywords: Mosquitoes; Borrachudos; Ecology; Genetics.

Topic: Fundamentos de Biodiversidade

Reviewed anonymously in the process of blind peer.
Received: 05/12/2020

Approved: $20 / 02 / 2021$
Willian Rodrigues da Costa Marinho (it) Universidade Federal do Rio de Janeiro, Brasil

http://lattes.cnpq.br/8236809033603146 http://orcid.org/0000-0002-2076-9648 will.bio2016@gmail.com

Ruann Guimarães dos Santos (iD Faculdade Cenecista de Rio das Ostras, Brasil

http://lattes.cnpq.br/7726682036401916 http://orcid.org/0000-0002-2805-4401 ruannguimaraes98@gmail.com

\section{Lucas Santos da Cruz (10)}

Universidade Federal do Rio de Janeiro, Brasil

http://lattes.cnpq.br/6914766001937665 http://orcid.org/0000-0002-4255-6045 Isdccruz@gmail.com
Isabelle Chagas Vilela Borges (iD Universidade Federal do Rio de Janeiro, Brasi http://lattes.cnpq.br/0694165383430516 http://orcid.org/0000-0002-5579-8158 isabellechagas8@gmail.com

\section{Beatriz Maravilha Medeiros}

Universidade Federal do Rio de Janeiro, Brasi http://lattes.cnpq.br/9582966121749704 http://orcid.org/0000-0003-1235-5741 bia.medeiros013@gmail.com

Rodrigo Alves da Silva (iD)

Universidade Estadual do Norte Fluminense Darcy Ribeiro, Brasil

http://lattes.cnpq.br/3179307210905645

http://orcid.org/0000-0002-6350-1465 rodrigo.silva1823@hotmail.com

\section{Aline Karl Araujo (iD}

Universidade Federal do Rio de Janeiro,

Brasil

http://lattes.cnpq.br/1158072953848391

http://orcid.org/0000-0002-8865-8880

alinekarl.ufri@gmail.com

Jackson de Souza Menezes (it)

Universidade Federal do Rio de Janeiro,

Brasil

http://lattes.cnpq.br/1039954814307345

http://orcid.org/0000-0002-3202-5742

jacksonmenezes@gmail.com

Natália Martins Feitosa (iD

Universidade Federal do Rio de Janeiro,

Brasil

http://lattes.cnpq.br/0947218221579614

http://orcid.org/0000-0001-9425-8018

nataliafeitosa@gmail.com
Ronaldo Figueiró Portella Pereira (iD) Centro Universitário Estadual da Zona Oeste, Brasil

http://lattes.cnpq.br/5561603703829476 http://orcid org/0000-0003-0762-1312 ronaldofigueiro@gmail.com

Rodrigo Nunes da Fonseca (ii) Universidade Federal do Rio de Janeiro, Brasil

http.//lattes cnpg br/5456237658132719

htp://attes.cnpq.br/545237658132719 rodrigo.nunes.da.fonseca@gmail.com

\section{Referencing this:}

MARINHO, W. R. C.; SANTOS, R. G.; CRUZ, L. S.; BORGES, I. C. V.; MEDEIROS, B. M.; SILVA, R. A.; ARAUJO, A. K.; MENEZES, J. S.; FEITOSA, N. M.; PEREIRA, R. F. P.; FONSECA, R. N.. Simulídeos (simuliidae: diptera) como objeto de estudo no Brasil e no mundo. Nature and Conservation, v.14, n.1, p.12-23, 2021. DOI:

http://doi.org/10.6008/CBPC2318-2881.2021.001.0002 


\section{INTRODUÇÃO}

O filo Arthropoda compreende mais de um milhão de espécies ocupando uma extensa variedade de nichos nos ecossistemas. As espécies desse filo apresentam apêndices articulados e um corpo segmentado, guardado por um exoesqueleto de quitina (HASSANIN, 2006).

Esse filo é considerado um dos mais importantes ecologicamente, em especial pelo processo de transmissão de grande parte do fluxo energético dos ecossistemas por esses seres, auxiliando a manutenção do equilíbrio ambiental (AQUINO et al., 2006). Na composição desse filo encontram-se inseridas as espécies representantes da Classe Insecta. Os insetos fazem parte do grupo mais abundante na Terra, compreendendo pelo menos $75 \%$ das espécies de animais terrestres e realizam serviços essenciais para a manutenção da maioria dos ecossistemas (GRIMALDI et al., 2005). Os insetos desempenham papéis ecológicos importantes, tais como ciclagem de nutrientes, polinização das plantas, dispersão de sementes, manutenção da estrutura e fertilidade do solo, tratamento de resíduos, controle das populações de organismos, além de serem fonte direta de alimento para inúmeras espécies animais. Há determinados insetos que são considerados espécieschave para a conservação do hábitat e das interações ecológicas como por exemplo, a abelha Apis mellifera, um inseto polinizador (FISHER, 1998).

Insetos apresentam corpo segmentado em cabeça, tórax, abdômen e três pares de patas. Ao longo de mais de 400 milhões de anos de evolução, esses organismos desenvolveram uma extraordinária capacidade adaptativa para viverem em quase todos os tipos de ecossistemas terrestres, exceto os mares (BORROR et al., 1969). O surgimento das asas possibilitou a esses animais a capacidade de voo, e com isso a exploração de diferentes habitat na busca de recursos e proteção (WILLE, 2002). Devido à possibilidade de ocupar novos ambientes e à variedade de hábitos alimentares, os insetos se estabeleceram como um grupo de grande sucesso evolutivo, proveniente do grande número de indivíduos e espécies (RODRIGUES, 2004). Além disso, o desenvolvimento dos insetos favoreceu a conquista e a exploração de diferentes ambientes, principalmente os insetos da ordem Diptera que em grande parte realizam seu desenvolvimento por holometabolia, ou seja, as fases juvenis são distintas da fase adulta e sobrevivem em diferentes ambientes (COSTA et al., 2006).

Entre os insetos, a ordem Diptera possui uma alta riqueza de espécies, com aproximadamente 152.000 espécies descritas (ALVARENGA et al., 2016). Os dípteros são cosmopolitas, ou seja, estão distribuídos por todos os continentes e são capazes de habitar diferentes localidades, principalmente os ambientes aquáticos como poças, rios, riachos e reservatórios de água artificiais, que são fundamentais para o desenvolvimento larval de muitos desses animais. Essa Ordem de insetos é considerada uma das mais diversificadas em termos de riqueza de espécies e exercem importantes funções como decompositores, polinizadores e controladores biológicos, reforçando ainda mais a notável importância dos mesmos (SOUZA et al., 2015).

Dentre os dípteros que apresentam importância ecológica, econômica, médica ou veterinária, encontra-se a família Simuliidae, dípteros com distribuição mundial, encontrados em todas as regiões do 
planeta, exceto nos polos (COPPO et al., 2010). Os insetos da família Simuliidae são dípteros nematóceros, conhecidos no Brasil como borrachudos, piuns ou casaquinhos-de-couro. Os ovos, larvas e pupas se desenvolvem em ambientes aquáticos e os adultos alados em ambientes terrestres, apresentando uma longevidade que pode atingir até quatro semanas (ADIS et al., 2007).

Os machos adultos de simulídeos se alimentam de sulco vegetal, enquanto as fêmeas apresentam hábitos antropofílicos ou zoofílicos, principalmente nos períodos da manhã e tarde, sendo o repasto sanguíneo das fêmeas associado à maturação dos ovócitos para eclosão de larvas, complementando assim o ciclo gonodotrófico (CROSSKEY, 1955).

As fêmeas de simulídeos estão entre os hematófagos mais irritantes ao ser humano e outros animais, pois as lesões das picadas em partes do corpo causam extensa irritabilidade à pele. Os simulídeos também podem atuar como vetores de doenças transmitidas por agentes etiológicos como bactérias, protozoários, nematoides e vírus (CERQUEIRA, 1967).

A família Simuliidae apresenta uma grande distribuição geográfica e grande importância médicaveterinária, pois inclui espécies que são vetores de agentes etiológicos de doenças, tanto para animais como para o homem (AMARAL et al., 2003). Dentre as espécies vetores, algumas são capazes de transmitir a Oncocercose, doença causada por uma microfilária Onchocerca volvulus, que se desenvolve no interior do inseto e é transmitida através da picada (MORAES, 1991).

Devido a essa capacidade vetorial e sua intensa zoofilia e antropofilia, os simulídeos afetam atividades turísticas e agropecuárias em regiões que apresentam alta incidência do inseto (FIGUEIRÓ et al. 2006). Assim, o controle desses insetos vem sendo realizado desde a década de 70 particularmente devido a sua importância no âmbito médico-sanitário e socioeconômico (NUNES et al., 2008).

A flutuação temporal da população de organismos como os simulídeos é influenciada por fatores químicos ou físicos. Fatores físicos como as alterações antrópicas podem proporcionar o aumento da população, levando consequentemente à ataques aos seres humanos, podendo também afetar sistemas agrícolas e o setor de turismo (DELLOME FILHO, 1991; 1992). A poluição contribui para o enriquecimento de matéria orgânica no ambiente, aumentando a quantidade de alimento, que, em geral favorece a proliferação de simulídeos. Todavia, a quantidade de alimento disponível não é o único fator que governa a prevalência e abundância desses organismos em determinado local. Por exemplo, as concentrações de oxigênio na água também podem influenciar a proliferação ou diminuição desses insetos, ou seja, rios com baixas taxas de oxigênio por diminuição na qualidade da água podem diminuir a proliferação dos simulídeos (CASTEX et al., 1988).

Dessa forma, alterações no ambiente podem contribuir para o aumento da população desses organismos, pois os simulídeos apresentam uma capacidade de responder a modificações ambientais de forma notável, uma vez que são organismos sensíveis a alterações de caráter biótico ou abiótico em seu habitat (CAMPOS et al., 2002). Uma explosão populacional de simulídeos em um determinado local pode se tornar um problema preocupante, uma vez que esses organismos são vetores de doenças e organismos 
incômodos às pessoas (TAUIL, 2002).

Esse trabalho teve como objetivo trazer aspectos gerais sobre a biologia e importância de estudos com simulídeos, além de demonstrar os diferentes campos em que esses organismos podem ser estudados, já que estudos com esses animais apresentam aplicabilidade em diferentes áreas da Biologia, Medicina ou Veterinária.

\section{METODOLOGIA}

O presente estudo apresenta dados referentes à Biologia e aplicabilidades de estudos com simulídeos. Foram utilizados como base de pesquisa para o presente trabalho, bibliografias como: livros, artigos, dissertações, teses e manuais retirados de veículos de divulgação digital: Scielo, Researchgate, Pubmed, Google Acadêmico para a obtenção de conteúdo referente ao tema a partir do ano de 1960 até 2020.

As palavras utilizadas para a pesquisa foram: Simulídeos, Biologia, Genética, Medicina, Estudos e Ambiental. Em um segundo momento, foram incluídas as palavras: Parasitologia, doenças e Meio Ambiente para ampliar a pesquisa nos bancos de dados.

\section{RESULTADOS E DISCUSSÃO}

\section{Aspectos biológicos dos simulídeos}

Os integrantes da classe Insecta tem características peculiares de desenvolvimento e muito diferentes entres seus integrantes. Na ordem díptera o desenvolvimento ocorre em quatro fases: ovo, larva, pupa e adultos (GRIMALDI et al., 2005).

A fase de ovo, isto é, embrionária, é a única do desenvolvimento em que o inseto não consegue se dispersar e se alimentar sendo, portanto, uma fase promissora para formulações de estratégias de controle. No caso dos simulídeos os ovos são depositados em substrato de rochas, folhas, galhos ou quaisquer objetos localizados próximos à correnteza de ambientes como rios, córregos ou riachos próximos a regiões de floresta ou mata (LANE et al., 2012).

Os ovos postos pelas fêmeas de simulídeos são cobertos por uma massa gelatinosa, utilizada para sua fixação e que impede seu deslocamento pela correnteza. A quantidade de ovos por oviposição pode variar, assim como o formato da mesma, mas cerca de 200 a 300 ovos são observados por postula (figura 1) e o tempo de desenvolvimento embrionário apresenta-se de quatro a seis dias (GAMBRELL et al., 1933; PETRY, 2005). O formato e a cor dos ovos variam de acordo com a espécie, podendo ser desde um amarelo claro a um marrom mais escuro com formatos subtriangulares ou ovais irregulares. Os embriões deixam os ovos como larvas em torno do sexto dia após a postula, podendo variar o tempo de acordo com as condições ambientais como temperatura, pH e característica da espécie (HAMADA et al., 2002; AZEVEDO et al., 2012; WAINFAS, 2015).

Após a eclosão, as larvas (figura 2) se fixam ao substrato utilizando dois sistemas de ventosas que a 
auxilia na locomoção e aderência, além de glândulas especializadas em secretar uma seda resistente que serve de cabo de ancoragem para que a larva não seja carregada em meio ao fluxo de água (HAMADA et al., 2014). Ao se fixar, a larva abre um par de apêndices modificados localizados na região frontal da sua caixa cefálica, conhecido como pentes cefálicos (FIGUEIRÓ et al., 2015). Essa estrutura é composta de filamentos que ajudam no processo de filtração dos materiais trazidos pela correnteza e que podem ser ingeridos pela larva. A partir de sua alimentação as larvas passam por sete a nove estágios de crescimento e amadurecimento, que varia de acordo com a espécie, até chegar a seu último estágio, que em geral poder ser identificado pela presença do histoblasto maduro, isto é uma estrutura precursora das asas, após seu amadurecimento no estágio de pupa, além disso as larvas possuem uma estrutura denominada pro-leg que auxilia sua locomoção (PETRY, 2005).

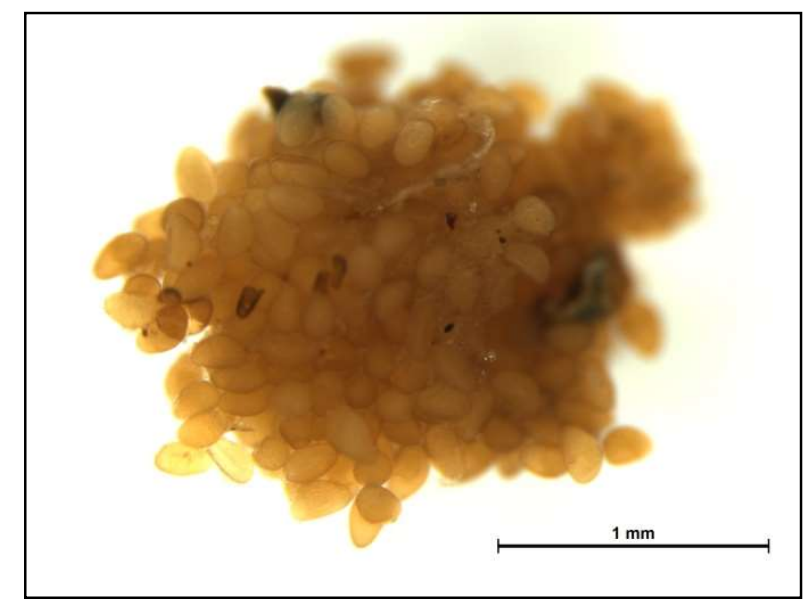

Imagem 1: Ovos de Simulium spp. Os ovos da Família Simuliidae apresentam um formato oval - triangular e uma coloração amarelada.

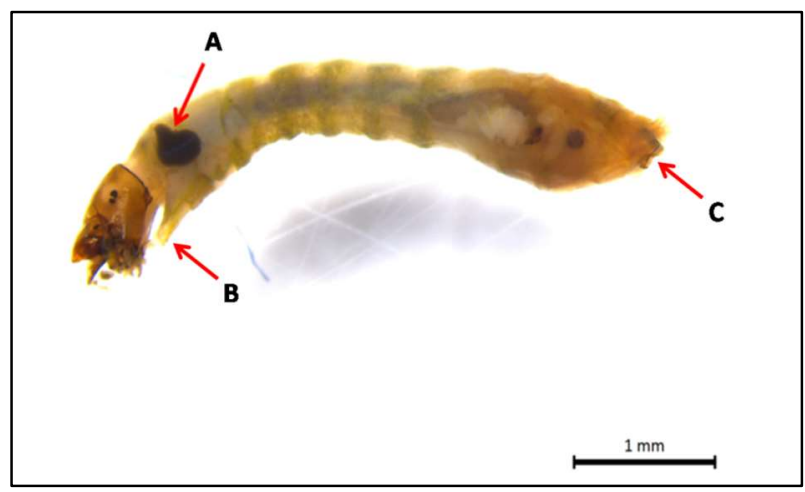

Imagem 2: Larva da Família Simuliidae. As setas em vermelho indicam em A- A região do histoblasto. $O$ histoblasto quando apresenta a coloração escura, mostra que a larva está em seu último instar conforme na figura. Em B- Região da pro-leg, importante para auxiliar a larva na locomoção, uma vez que estas apresentam locomoção mede-palmo. Em C-Região do disco anal, onde há um sistema de ganchos que fazem com que a larva se prenda ao substrato e não seja carregada pela força da correnteza.

Ao atingir seu último estágio larval, os simulídeos iniciam o desenvolvimento de um casulo constituído de seda e se fixam a substratos formando uma pupa (figura 3), isto é, um estágio latente de transformação onde ocorre uma extensa reorganização estrutural e fluídica necessária para a formação do indivíduo adulto. O formato da pupa varia de acordo com a espécie; assim como a estrutura do casulo, variando entre formatos de chinelo (chineliforme), sapato (sapatiforme) ou sem formato definido (HAMADA et al., 2014). Além disso, características das tramas da seda podem ser soltas ou entrelaçadas (RIBEIRO, 2018). Estas características morfológicas observadas na parte externa das pupas e de seus casulos são essenciais para a classificação taxonômica das espécies de simulídeos.

Depois do período de desenvolvimento como pupa, o adulto (figura 4) emerge do ambiente aquático com objetivo de acasalar e perpetuar sua linhagem. Para tal feito, os adultos dispõem de um par de asas que Ihes confere maior mobilidade para conseguir alimento, ou nos casos das fêmeas realizarem o repasto sanguíneo (DEL CARRO, 2012). De forma interessante, adultos de simulídeos se assemelham muito mais 
morfologicamente com moscas do que com outras espécies de mosquitos e possuem muitas vezes uma coloração escura daí o nome em inglês 'black fly'.

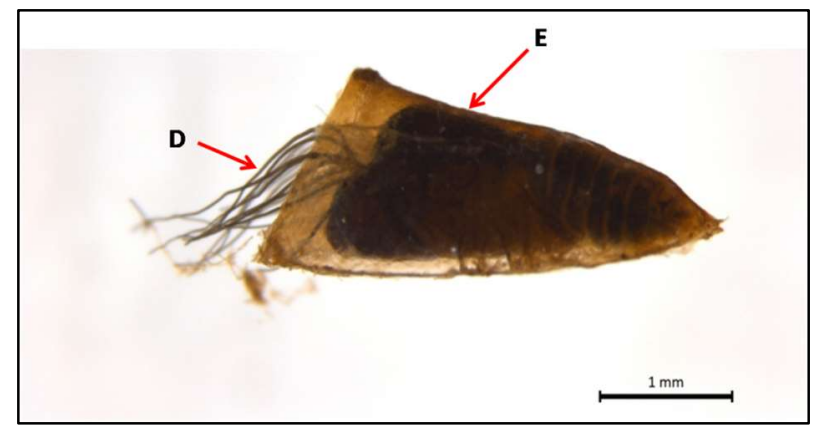

Imagem 3: Pupa da Família Simuliidae com casulo em forma de chinelo. As setas mostram em D- Filamentos braquiais arqueados e em E- casulo com tramas compactas. Esse é o estágio intermediário entre a larva e $o$ adulto.

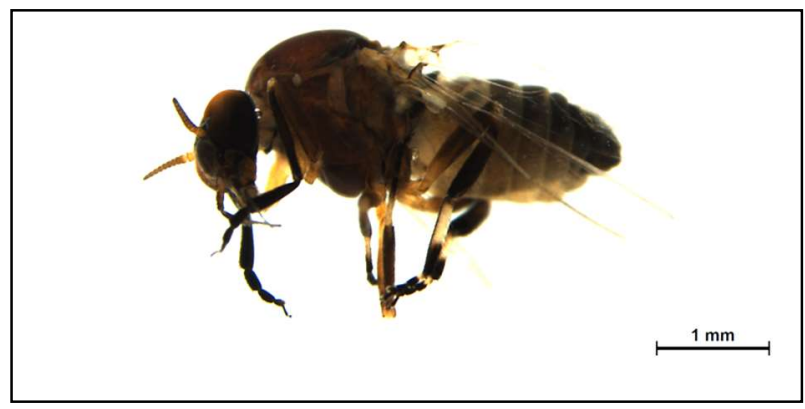

Imagem 4: Fêmea adulta da Família Simuliidae. Neste estágio do desenvolvimento logo após a eclosão, o adulto macho ou fêmea se alimenta de néctar de plantas. Posteriormente as fêmeas também se alimentam de sangue obtido a partir da hematofagia de algum vertebrado e utilizam desta fonte para realizar o processo de geração dos seus ovos, a ovogênese.

Algumas espécies de simulídeos, assim como outros dípteros, têm hábitos hematófagos como é o caso de alguns mosquitos dos gêneros Aedes, Culex e Anopheles, vetores de diversas doenças negligenciadas no mundo. As fêmeas realizam repasto sanguíneo para obtenção de nutrientes presentes no sangue essenciais para a geração e maturação dos ovos. O suprimento de sangue é obtido a partir picadas em animais vertebrados e a hematofagia é um processo essencial para a conclusão do ciclo de vida do inseto (RIO GRANDE DO SUL, 2006).

\section{Importância ambiental da família simuliidae}

Assim como qualquer organismo vivo, os simulídeos desempenham funções dentro de um ecossistema complexo muitas vezes ocupando nichos e funções diferentes de acordo com seu estágio de vida, similar ao que ocorre com diversos integrantes da classe Insecta (MOULTON, 1998).

No estágio larval os simulídeos se alimentam a partir da filtração de materiais orgânicos dispersos na água como um organismo bioindicador. Mudanças nos indicadores de qualidade da água como $\mathrm{pH}$, salinidade ou nível de matéria orgânica dissolvida são importantes para determinar a saúde de um ambiente aquático bem como o número de espécies e de indivíduos de simulídeos encontrados (LOZOVEI et al., 2004).

As larvas e pupas dos simulídeos são fontes de nutrientes essenciais para os predadores presentes nos riachos como crustáceos, peixes, ninfas e larvas de outros insetos pelo fato de captar materiais dispersos na correnteza, formando assim a base da teia alimentar de um pequeno ecossistema como um riacho (CURRIE et al., 2008). Quando eclode do seu estágio de pupa, os machos adultos desempenham o papel de polinizadores, se alimentando de néctar de flores e carreando partículas de pólen que auxiliam na reprodução da flora. Por outro lado fêmeas apresentam hábitos antropofílicos ou zoofílicos, principalmente, nos períodos da manhã e tarde, sendo o repasto sanguíneo das fêmeas associado à maturação dos ovócitos (CROSSKEY, 1955). 
Durante o processo de repasto sanguíneo ocorre o contato entre a corrente sanguínea do vertebrado, o trato bucal e sistema digestório do simulídeo. A ingestão de sangue pode levar a entrada concomitante de parasitas passiveis de serem transmitidos para outros vertebrados nos próximos repastos sanguíneos. Assim, os simulídeos possuem também importância médico-veterinária, muitas vezes sendo está negligenciada (SHELLEY et al., 1976).

\section{Importância médico-veterinária do simulídeo}

A hematofagia apareceu diversas vezes na evolução dos insetos em particular na ordem Diptera, sendo estes insetos muitas vezes transmissores de doenças em regiões tropicais ou subtropicais. Exemplos bem conhecidos e prevalentes são os mosquitos Aedes aegypti transmissor de diversas arboviroses como Dengue, Zika e Chikungunya bem como mosquitos do gênero Culex transmissor da filariose causada pelo nematódeo Wuchereria bancrofti (NOWAK et al., 2018).

Os simulídeos também possuem importância médica-sanitária por serem vetores de diversos parasitas de humanos e animais. O principal e mais conhecido parasita é o Onchocerca volvulus, verme causador da Oncocercose a comumente conhecida cegueira dos rios, pelo fato do parasita acometer região dos olhos gerando assim problemas na visão ou até cegueira completa (ANBALAGAN et al., 2013). Este parasita é comumente encontrado em regiões da África, podendo ser encontrado também em regiões do Norte e Nordeste do Brasil afetando populações ribeirinhas, moradores de cidades próximas a regiões de risco e fazendeiros de gado de corte bem porcos, cabras e ovelhas podendo fazer com que perca inúmeras cabeças gerando prejuízo ao produtor (VERONESI, 1991; HERZAG NETO et al., 2009; FIGUEIRÓ et al., 2012).

A transmissão do parasita se dá pelo aparelho bucal do inseto fêmea que ao realizar o repasto sanguíneo libera uma secreção que funciona como anestésico e anticoagulante, ao mesmo tempo em que rasga a pele com o seu aparelho bucal gerando feridas com gotículas de sangue que servem como porta de entrada para o verme parasita entrar como larva na corrente sanguínea, crescer e se tornar adulto, se reproduzir gerando microfilárias que vão se alojar em regiões como os olhos ou regiões da pele formando nódulos e inchaços (KARAM et al., 1987; UDALL, 2007).

A Oncocercose não é a única enfermidade gerada pela picada dos simulídeos, sendo estes insetos capazes também de transmitir outras filarias como no caso da Mansonelose, encontrada por toda a América do Sul, que muitas vezes pode ser uma doença assintomática por anos até gerar sintomas desde dores em articulações até problemas oculares e lesões. Além disso, as picadas de simulídeos podem levar a reações alérgicas dermatológicas, incluindo a possibilidade de desenvolver doenças autoimunes devido a picada do inseto (TAVARES, 1981; GARRIDO et al., 2000).

Tanto no contexto da conservação, biomonitoramento ou médico-veterinário é importante conhecer aspectos relevantes da biologia dos simulídeos. Nos itens abaixo são destacados aspectos importantes e pouco conhecidos da biologia destes insetos e que se encontram na fronteira do conhecimento do grupo. 


\section{Aspectos negligenciados: diversidade genética, filogenia e número de espécies do grupo}

A família Simuliidae é uma família representada por dípteros aquáticos que se encontram ausentes apenas na Antártica, desertos e ilhas onde por falta de riachos e água corrente ou existência de temperaturas extremas, o desenvolvimento do estágio larval é inviável. Análises taxonômicas baseadas em características morfológicas sugerem que está Família possuiria aproximadamente 2.328 espécies, incluindo 12 fósseis (MENZEL et al., 2019). Estudos de filogenia molecular de insetos tem avançado enormemente nos últimos devido as novas tecnologias de sequenciamento de DNA (NGS em inglês - Next Generation Sequence). Particularmente importante, estudos de filogenômica e filotranscriptômica, nos quais grande número de sequências de DNA de diversas espécies, famílias e ordens são investigadas tem revolucionado os estudos das relações filogenéticas entre os organismos. Estes estudos moleculares sugerem que a origem dos insetos ocorreu no início do Ordoviciano [ 479 milhões de anos atrás (Ma), dos insetos alados no início do Devoniano ( 406 Ma), o surgimento dos holometábolos (345 Ma atrás) e dos Diptera (245 Ma) (MISOF et al., 2014). Poucos estudos moleculares buscaram investigar as relações filogenéticas entre espécies de simulídeos quando comparados com estudos outros Dipteras modelo como os drosofilídeos. No mundo essa família é conhecida particularmente devido aos casos de espécies crípticas, isto é, duas ou mais espécies que são morfologicamente indistinguíveis, mas geneticamente bastante diferentes (ANDRADE-SOUZA et al., 2017). Podem ser diferenciadas também, ecologicamente, através de alguns comportamentos distintos.

Nos últimos anos análises moleculares feitas a partir de sequências de DNA mitocondrial, principalmente com a subunidade I do gene Citocromo Oxidase (COI) tem colaborado para determinação das espécies, mostrando a diversidade dessa família e fazendo principalmente, inferências filogenéticas em simulídeos (RIVERA et al., 2009). Por último, vários pesquisadores do mundo se uniram para sequenciar o genoma destes mosquitos (BROCKHOUSE et al., 2011).

\section{Aspectos negligenciados: a biologia evolutiva do desenvolvimento}

A ciência conhecida como Biologia Evolutiva do Desenvolvimento, estuda a relação existente entre a evolução e o desenvolvimento dos organismos (ALMEIDA et al., 2010). A regulação da expressão de genes no embrião regula as transformações morfológicas no indivíduo desde seu desenvolvimento embrionário até a fase adulta. Os estudos dos genes que agem no controle do desenvolvimento estenderam as possibilidades para estudos visando entender como a evolução pode ocorrer (RIDLEY, 2009). Dentre todos os animais, a mosca-da-fruta Drosophila melanogaster é o mais conhecido organismo-modelo de biologia do desenvolvimento, genética, comportamento, sendo, portanto, um modelo extremamente importante para estudos de biologia e medicina (ALVARENGA et al., 2016). Conhecida popularmente como mosca-da-fruta, D. melanogaster que possui diversas características consideradas derivadas entre os dípteros. Dentre estas características destaca-se a presença de uma única membrana extraembrionária reduzida quando comparado com dípteros representantes de grupos mais basais como o Culicidae mosquito Aedes aegypti (ALVARENGA et al., 2016). 
Mais recentemente o papel do meio-ambiente como agente seletor de novos fenótipos tem sido discutido além do componente genético na chamada Eco-Evo-Devo (GILBERT, 2008).

Neste contexto, a família Simullidae constitui-se em um modelo de estudo extremamente interessante do ponto de vista da Eco-Evo-Devo por sua nítida relação e dependência de ambientes de água corrente, particularmente no desenvolvimento de seus estágios imaturos nos rios com cachoeiras. Várias estruturas importantes morfo-funcionalmente são desenvolvidas durante os estágios larvais desta família descritas são essenciais para o ciclo de vida dos simulídeos tais como seu sistema de ganchos que fazem com que a larva se prenda ao substrato, glândulas secretoras de seda para ancoragem e os pentes cefálicos que auxiliam na alimentação. Até o presente momento não se conhecem os mecanismos moleculares envolvidos no desenvolvimento destas estruturas durante o desenvolvimento larval dos simulídeos.

Os estudos com organismos considerados 'não-modelos' têm revelado muitos pontos em comum no desenvolvimento de artrópodes. Contudo, há estudos que mostram divergências na forma e funcionamento de artrópodes, ressaltando-se os estágios de ovo e adultos. Estudos recentes realizados em diversas espécies de Diptera (YOON et al., 2019) demonstraram que os determinantes anteriores e posteriores, isto é, as moléculas responsáveis pela determinação das regiões da cabeça e do abdômen são diferentes entre as diversas espécies de Diptera. Neste estudo, foram analisados os determinantes anteriores e posteriores dos ovos do vetor da leishmaniose Lutzomyia longipalis e em mosquitos vetores de doenças como os culicídeos dos gêneros Culex e Aedes e os anofelinos do gênero Anopheles. Uma grande variação das moléculas utilizadas para a determinação das regiões anteriores e posteriores nestes insetos foi observada, demonstrando a importância do estudo de espécies não-modelo, isto é, não espécies não-usuais nos estudos de Evo-Devo. Por exemplo, enquanto vertebrados estabelecem a formação do eixo antero-posterior a partir de modulação da via de Wnt, insetos da Ordem Diptera como o inseto-modelo D. melanogaster adquiriram outros genes e mecanismos independentes para formação da cabeça e abdômen. Recentemente, Yoon et al. (2019) demonstraram que os Tipulidae (típulas, moscas-grua ou mosquitos-gigantes em inglês Crane fly), um grupo de ramificação basal (basally branching-Nephrotoma) entre os Diptera, utiliza um membro da via de Wnt para determinação da região anterior Estes resultados sugerem que Wnt teria este papel ancestral de determinação anterior em Dipteras ancestrais e por consequência nos demais insetos e nos demais animais. Dípteros em posições de ramificação derivadas como moscas-da-fruta da espécie $D$. melanogaster adquiriram outros mecanismos para o estabelecimento da região da cabeça, como a expressão do fator de transcrição bicoid, essencial para o desenvolvimento embrionário desta espécie, mas cuja origem é estimada cerca de 150 milhões de anos atrás enquanto a origem dos Diptera remonta a 240-250 milhões de anos atrás.

Assim, o estudo das características presentes em grupos de espécies com características ancestrais e o surgimento de novas características em grupos derivados são importantes temas de estudo para EvoDevo de artrópodes. Conforme demonstrado pelo exemplo acima, estudos de biologia do desenvolvimento com um relativo número de espécies localizadas em grupos estratégicos na filogenia são essenciais (SOMMER, 2009). Neste contexto os simulídeos com sua importante posição filogenética de ramificação 
basal entre os díptera e suas diversas características morfológicas com características de aparente valor adaptativo nos ambientes aquáticos, constituem-se como excelente exemplo de organismo "não-modelo" da entomofauna do nosso país e da América Latina (MARQUES-SOUZA et al., 2012; MARCELINNI et al., 2016)

\section{CONCLUSÕES}

Conclui-se que os simulídeos são organismos que apresentam tanto potencial para transmissão de patógenos, quanto grande importância na cadeia trófica como organismos bioindicadores. Estudos recentes de Evo-Devo com outras espécies de dípteros sugerem que, pela sua posição filogenética e características morfológicas peculiares, o estudo com simulídeos pode ser bastante importante para a compreensão dos processos evolutivos dos díptera.

\section{REFERÊNCIAS}

ADIS, J.; ARIAS, J. R.; RUEDA-DELGADO, G.; WANTZEN, K. M. Aquatic Biodiversity in Latin America. 2007.

ALMEIDA, A. M. R. D.; EL-HANI, C. N.. Um exame históricofilosófico da biologia evolutiva do desenvolvimento. Scientiae Studia, v.8, n.1, 2010.

ALVARENGA, A. D. S.; OLIVEIRA, F. A. D.; TOBIAS-SANTOS, V.; NETO, L. G. R.; MENEZES, J. D. S.; MARTINS-FEITOSA, N.; FONSECA, R. N. D.. Biologia evolutiva do desenvolvimento de Artrópodes: uma visão brasileira. ACTA SCIENTIAE \& TECHNICAE, v.4, n.2, 2016.

AMARAL, A. M. D.; HERZOG, M. M.. Coleção de simuliídeos (Diptera-Simuliidae) de Adolpho Lutz, sua história e importância. História, Ciências, Saúde-Manguinhos, v.10, n.1, 2003. DOI: http://dx.doi.org/10.1590/S0104$\underline{59702003000100009}$

ANDRADE-SOUZA, V.; SILVA, J. G.; HAMADA, N.. Phylogeography and population diversity of Simulium hirtipupa Lutz (Diptera: Simuliidae) based on mitochondrial COI sequences. Plos One, v.12, n.12, 2017. DOI: https://doi.org/10.1371/journal.pone.0190091

ANBALAGAN, S.; PRASANNA, V. A.; DINAKARAN, S.; KRISHNAN, M.. Molecular Phylogeny and Vector Potential of Black Flies (Diptera: Simuliidae) in India. IJALS, v.6, n.5, (2013).

AQUINO, A. M. D.; AGUIAR-MENEZES, E. D. L.; QUEIROZ, J. M. D.. Recomendações para coleta de artrópodes terrestres por armadilhas de queda ('Pitfall-Traps'). Embrapa Agrobiologia-Circular Técnica (INFOTECA-E), 2006.

BORROR, D. J.; DELONG, D. M.. Introdução ao estudo dos insetos. Rio de Janeiro: USAID, 1969.

BROCKHOUSE, C.; PAPANICOLAOU, A.; POST, R.; BOAKYE, D. CUPP, E. W.; PFRENDER, M.; COLBOURNE, J. K.. Genome Sequencing white paper for the black fly disease vectors Simulium sp. Vector Base, 2011.

CAMPOS, J.; ANDRADE, C. F. S.. Resistência a inseticidas em populações de Simulium (Diptera, Simuliidae). Cadernos de Saúde Pública, v.18, n.3, 2002. DOI:

https://doi.org/10.1590/S0102-311X2002000300010

CASTEX, M.; FUENTES, O.; MARQUETTI, M. D.. Breeding places of Simulium quadrivittatum Loew, 1862 (Diptera: Simuliidae) in Isla de la JuventuD. Revista Cubana de Medicina Tropical, v.40, n.3, 1988.

CERQUEIRA, N.. Simuliidae da Amazônia III: Sobre o Gênero "Simulium" Latreille, 1802 (Diptera, Nematocera). Atas do Simpósio Sobre a Biota Amazônica, v.5, p.127-139, 1967.

COPPO, T. L.; LOPES, J.. Diversidade de Simuliidae (Diptera: Nematocera) de três cursos d'água no parque ecológico da Klabin SA-Telêmaco Borba, Estado do Paraná. Semina: Ciências Biológicas e da Saúde, v.31, n.1, 2010.

COSTA, C.; IDE, S.; SIMONKA, C. E.. Metamorfosis y Evolución. Insectos Inmaduros: Metamorfosis e Identificación, v.5, p.1-233, 2006.

CROSSKEY, R. W.. Observations on the bionomics of adult Simulium damnosum Theobald (Diptera, Simuliidae) in Northern Nigeria. Annals of Tropical Medicine \& Parasitology, v.49, n.2, 1955. DOI: https://doi.org/10.1080/00034983.1955.11685659

CURRIE, D. C.; ADLER, P. H.. Global diversity of black flies (Diptera: Simuliidae) in freshwater. Developments in Hydrobiology, v.198, 2008.

DEL CARRO, K. B.. Influência dos fatores ambientais em diferentes escalas espaciais sobre a distribuição de Simulídeos (Diptera: Nematocera) em Córregos Tropicais. Dissertação (Mestrado em Biodiversidade Tropical) Universidade Federal do Espírito Santo, São Mateus, 2012.

DELLOME FILHO, J.. Simuliofauna do rio Marumbi (Morretes, PR, Brasil). I. Coleta e criação; dados meteorológicos e físicoquímicos do criadouro; adultos (Diptera, Simuliidae). Acta Biológica Paranaense, v.20, n.1-4, 1991.

DELLOME FILHO, J.. Simuliofauna do rio Marumbi, Morretes, Paraná, Brasil. II. Substratos naturais e artificiais dos 
imaturos e fauna associada (Diptera, Simuliidae). Acta Biológica Paranaense, v.21, n.1-4, 1992.

FIGUEIRÓ, R.; GIL-AZEVEDO, L. H.; MAIA-HERZOG, M.; MONTEIRO, R. F.. Diversity and microdistribution of black fly (Diptera: Simuliidae) assemblages in the tropical savanna streams of the Brazilian Cerrado. Mem. Inst. Oswaldo Cruz, v.107, n.3, 2012. DOI: https://doi.org/10.1590/S0074$\underline{02762012000300011}$

FIGUEIRÓ, R.; ARAÚJO-COUTINHO, C. J.; AZEVEDO, L. H. G.; NASCIMENTO, É. S.; MONTEIRO, R. F.. Spatial and temporal distribution of blackflies (Diptera: Simuliidae) in the Itatiaia National Park, Brazil. Neotropical Entomology, v.35, n.4, 2006. DOI: http://dx.doi.org/10.1590/S1519566x2006000400018

FIGUEIRÓ, R.; CALVET, A.; GIL-AZEVEDO, L. H.; DOCILE, T. N.; MONTEIRO, R. F.; MAIA-HERZOG, M.. Evidence of phenotypic plasticity of larvae of Simulium subpallidum Lutz in different streams from the Brazilian Cerrado. Revista Brasileira de Entomologia, v.59, n.1, 2015. DOI: https://doi.org/10.1016/i.rbe.2015.02.003

FIGUEIRÓ, R.; GIL-AZEVEDO, L. H.. The role of neotropical blackflies (Diptera: Simuliidae) as vectors on the onchocerciasis: a short overview of the ecology behind the disease. Oecologia Australis, v.14, n.3, 2010.

FISHER, B. L.. Insect behavior and ecology in conservation: preserving functional species interactions. Annals of the Entomological Society of America, v.91, n.2, p.155-158, 1998. DOI: https://doi.org/10.1093/aesa/91.2.155

GAMBRELL, F.; JAHN, L. A.. The embryology of the black fly, Simulium pictipes Hagen. Annals of the Entomological Society of America, v.26, n.4, p.641-671, 1933. DOI: https://doi.org/10.1093/aesa/26.4.641

GARRIDO, C.; CAMPOS, M.. First report of presumed parasitic keratitis in Indians from the Brazilian Amazon. CORNEA, v.19, n.6, p.817-819, 2000.

GILBERT, S. F.; EPEL, D.. Ecological Developmental Biology. Sunderland: Sinauer Associates, 2008.

GRIMALDI, D.; ENGEI, M. S.. Evolution of the Insects. Cambridge University Press, 2005.

HAMADA, N.; MCCREADIE, J. W.; ADLER, P. H.. Species richness and spatial distribution of blackflies (Diptera: Simuliidae) in streams of Central Amazonia, Brazil. Freshwater Biology, v.47, n.1, p.31-40, 2002; DOI: https://doi.org/10.1046/j.1365-2427.2002.00778.x

HAMADA, N.; NESSIMIAN, J. L.; QUERINO, R. B.. Insetos aquáticos na Amazônia brasileira: taxonomia, biologia e ecologia, Manaus: INPA, 2014.

HASSANIN, A.. Phylogeny of Arthropoda inferred from mitochondrial sequences: strategies for limiting the misleading effects of multiple changes in pattern and rates of substitution. Molecular Phylogenetics and Evolution, v.38, n.1, p.100-116, 2006. DOI:

https://doi.org/10.1016/i.ympev.2005.09.012
HERZAG NETO, G.; JAEGGER, K.; MARCHON-SILVA, V.; CALVÃO-BRITO, R. H. S.; VIEIRA, J. B.; BANIC, D. M.; MAIAHERZOG, M.. Eye disease related to onchocerciasis: A clinical study in the Aratha-ú, Yanomami Tribe, Roraima State, Brazil. Acta Tropica v.112, n.2, p.115-119, 2009. DOI: https://doi.org/10.1016/j.actatropica.2009.07.006

KARAM, M.; SCHULZ-KEY, H.; REMME J.. Population dynamics of Onchocerca volvulus after 7 to 8 years of vector control in West Africa. Acta Tropica, v.44, n.4, 1987.

LANE, R. P.; CROSSKEY, R. W.. Medical insects and arachnids. Springer: Science \& Business Media, 1993.

LOZOVEI, A. L.; PETRY, F.; SANTOS NETO, L. G. D.; FERRAZ, M. E.. Levantamento das espécies de Simulium (Diptera, Simuliidae), Riacho dos Padres, município de Almirante Tamandaré, Paraná, Brasil. Revista Brasileira de Entomologia, v.48, n.1, 2004. DOI: https://doi.org/10.1590/S0085-56262004000100015

MARCELINNI, S.; GONZÁLEZ, F.; SARRAZIN, F. A.; PABÓNMORA, N.; BENÍTEZ, M.; PIÑEYRO-NELSON, A.; REZENDE, L. G.; MALDONADO, E.; SCHNEIDER, N.P.; GRIZANTE, B. M.; FONSECA, N. R.; VERGARA-SILVA, F.; SUAZA-GAVIRIA, V.; ZUMAJO-CARDONA, C.; ZATTARA, E. E.; CASASA, S.; SUÁREZBARON, H.; BROWN, D. F.. Evolutionary Developmental Biology (Evo-Devo) Research in Latin America. Journal of Experimental Zoology Part B: Molecular and Developmental Evolution, v.328, n.1-2, p.5-40, 2017. DOI: https://doi.org/10.1002/jez.b.22687

MARQUES-SOUZA, H.; SCHENEIDER I.; KOHLSDORF, T.; NUNES D. F.. Evo-Devo verde-amarela: biologia evolutiva do desenvolvimento ganha espaço no Brasil. Ciência Hoje, São Paulo, v.208, p.39-42, 2012.

MENZEL, T. C.; HENTGES, S. M.; TATAJE, D. A. R.; STRIEDER, M. N.. Diversity and spatial distribution of black flies (Diptera: Simuliidae) in the ljuí river drainage basin, Rio Grande do Sul, Brazil. Entomo Brasilis, v.12, n.2, 2019. DOI: https://doi.org/10.12741/ebrasilis.v12i2.845

MISOF, B.; LIU, S.; MEUSEMANN, K.; PETERS, R. S.; DONATH, A.; MAYER, C.; FRANDSEN, B. P.; FLOURI, T.; BEUTEL, R.; NIEHUIS, O.; PETERSEN, M.; IZQUIERDO-CARRASCO, F.; WAPPLER, T.; RUST, J.; ABERER, A. J.; ASPÖCK, U.; ASPÖCK, H.; BARTEL, D.; BLANKE, A.; BERGER, S.; BÖHM, A.; BUCKLEY, T. R.; CALCOTT, B.; CHEN, J.; FRIEDRICH, F.; FUKUI, M.; FUJITA, M.; GREVE, C.; GROBE, P.; GU, S.; HUANG, Y.; JERMIIN, L. S.; KAWAHARA, A. Y.; KROGMANN, L.; KUBIAK, M.; LANFEAR, R.; LETSCH, H.; LI, Y.; LI, Z.; LU, H.; MACHIDA, R.; MASHIMO, Y.; KAPLI, P.; MCKENNA, D. D.; MENG, G.; NAKAGAKI, Y.; NAVARRETE-HEREDIA, J. L.; OTT, M.; OU, Y.; PASS, G.; PODSIADLOWSKI, L.; POHL, H.; VON REUMONT, B. M.; SCHÜTTE, K.; SEKIYA, K.; SHIMIZU, S.; SLIPINSKI, A.; STAMATAKIS, A.; CANTICO.; SUI, X.; SZUCSICH, N, U.; TAN, M.; TAN, X.; TANG, M.; TANG, J.; TIMELTHALER, G.; TOMIZIKA, S.; TRAUTWEIN, M.; TONG, X.; UCHIFUNE, T.; WALZL, M. G.; WIEGMANN, B. M.; WILBRANDT, J.; WIPFLER, B.; WONG, T. K.; WU, QIONG.; WU, G.; XIE, Y.; YANG, S.; YANG, Q.; YEATER, D. K.; YOSHIZAWA, K.; ZHANG, Q.; ZHANG, R.; ZHANG, W.; ZHANG, Y.; ZHAO, J.; ZHOU, C.; ZHOU, L.; ZIESMANN, T.; ZOU, S.; LI, Y.; XU, X.; ZHANG, Y.; YANG, H.; WANG, J.; WANG, J.; KJER, K. M.; ZHOU, X.. 
Phylogenomics resolves the timing and pattern of insect evolution. Science, New York, v.346, n.6210, 2014.

MORAES, M. A.. Oncocercose entre os índios Yanomámi. Cadernos de Saúde Pública, v.7, p.503-514, 1991.

MOULTON, T. P.. Saúde e integridade do ecossistema eo papel dos insetos aquáticos. Oecologia Brasiliensis, v.5, n.1, 1998.

NOWAK, G. R.; RAGONHA, F. H.. A evolução e potencialização do Aedes aegypti em relação às doenças no Brasil e no estado do Paraná. Arquivos do Museu Dinâmico Interdisciplinar, v.22, n.1, p.48-78, 2018. DOI: https://doi.org/10.4025/arqmudi.v22i1.41521

NUNES, T. C.; RIBEIRO, R. S.; FARIA, P. R. G. V.; SILVA JUNIOR, N. J.. Vetores de Importância Médica na à rea de Influência da Pequena Central Hidrelétrica Mosquitão-Goiás. Revista EVS-Revista de Ciências Ambientais e Saúde, v.35, n.6, p.1085-1105, 2008. DOI: http://dx.doi.org/10.18224/est.v35i6.765

PETRY, F.. Aspectos biológicos de fertilidade e ciclo evolutivo de espécies de Simulium (Diptera, Simuliidae) e susceptibilidade de suas larvas em bioensaios laboratoriais com formulados de Bacillus thuringiensis israelensis em aparato elaborado. Dissertação (Mestrado em microbiologia, parasitologia e patologia) - Universidade Federal do Paraná, Curitiba, 2005.

RIBEIRO, L. M. L.. Inventário bibliográfico dos estudos envolvendo Diptera: Simuliidae em áreas impactadas por empreendimentos de grande porte. Monografia (Especialização em entomologia Médica) - Fundação Oswaldo Cruz, Rio de Janeiro, 2018.

RIDLEY, M.. Evolução. Artmed, 2009.

RIO GRANDE DO SUL. Simulídeos: guia para orientação aos municípios sobre manejo integrado, controle e gestão de insetos da família simuliidae (diptera, nematocera) no Rio Grande do Sul, 2006.

RIVERA, J.; CURRIE, D. C.. Identification of Nearctic black flies using DNA barcodes (Diptera: Simuliidae). Molecular Ecology Resources, v.9, n.1, p.224-236, 2009. DOI: https://doi.org/10.1111/j.1755-0998.2009.02648.x

RODRIGUES, W. C.. Fatores que influenciam no desenvolvimento dos insetos. Info Insetos, v.1, n.4, p.1-4, 2004.
SCHMIDT-OTT, U.; LYNCH, J. A.. Emerging developmental genetic model systems in holometabolous insects. Current Opinion in Genetics \& Development, v.39, p.116-128, 2016. DOI: https://doi.org/10.1016/j.gde.2016.06.004

SHELLEY, A. J.; MELLO J. A. S. N. D.; REES, R. G. O. Observações preliminares sobre a transmissão de oncocercose no rio Toototobi, Amazonas, Brasil. Acta Amazônica v.6, n.3, 1976. DOI:

https://doi.org/10.1590/1809-43921976063327

SOMMER, R. J.. The future of evo-devo: model systems and evolutionary theory. Nature Reviews Genetics, v.10, p.416422, 2009.

SOUZA, M. H.; VIEIRA, B. D. C. R.; OLIVEIRA, A. P. G.; AMARAL, A. A.. Macrofauna do solo. Enciclopédia Biosfera v.11, n.22, p.115-131, 2015.

TAUIL, P. L.. Controle de doenças transmitidas por vetores no Sistema Único de Saúde. Informe Epidemiológico do SUS, v.11, n.2, 2002. DOI: http://dx.doi.org/10.5123/S010416732002000200001

TAVARES, A. D. M.. Estudo da infecção por Mansonella ozzardi. Dissertação (Mestrado) - Universidade de Brasília, Brasília, 1981.

UDALL, D. N.. Recent updates on onchocerciasis: diagnosis and treatment. Clinical Infectious Diseases, v.44, n.1, p.5360, 2007. DOI: https://doi.org/10.1086/509325

VERONESI, R.. Doenças infecciosas e parasitárias. Revista do Instituto de Medicina Tropical de São Paulo, v.33, n.4, 1991. DOI: https://doi.org/10.1590/S0036-46651991000400018

WAINFAS, R. L.. Distribuição espacial e temporal de Simuliidae (Diptera) em córregos sob a influência de fatores abióticos e antrópicos da área da UHE peixeangical, Tocantins, Brasil. Dissertação (Mestrado em Biodiversdade e saúde) - Instituto Oswaldo Cruz, Rio de Janeiro, 2015.

WILLE, A.. The phylogeny and relationships between the insect orders. Revista de biologia tropical, v.50, n.2, 2002.

YOON, Y.; KLOMP, J.; MARTIN-MARTIN, I.; CRISCIONE, F.; CALVO, E.; RIBEIRO, J.; SCHMIDT-OTT, U.. Embryo polarity in moth flies and mosquitoes relies on distinct old genes with localized transcript isoforms. eLife, v.8, 2019. DOI: https://doi.org/10.7554/eLife.46711.001

A CBPC - Companhia Brasileira de Produção Científica (CNPJ: 11.221.422/0001-03) detém os direitos materiais desta publicação. Os direitos referem-se à publicação do trabalho em qualquer parte do mundo, incluindo os direitos às renovações, expansões e disseminações da contribuição, bem como outros direitos subsidiários. Todos os trabalhos publicados eletronicamente poderão posteriormente ser publicados em coletâneas impressas sob coordenação da Sustenere Publishing, da Companhia Brasileira de Produção Científica e seus parceiros autorizados. Os (as) autores (as) preservam os direitos autorais, mas não têm permissão para a publicação da contribuição em outro meio, impresso ou digital, em português ou em tradução. 